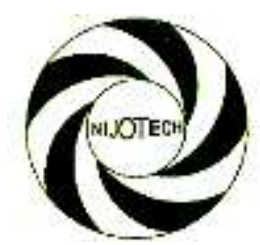

Nigerian Journal of Technology (NIJOTECH)

Vol. 38, No. 1, January 2019, pp. 134 - 141

Copyright@ Faculty of Engineering, University of Nigeria, Nsukka

Print ISSN: 0331-8443, Electronic ISSN: 2467-8821 www.nijotech.com

http://dx.doi.org/10.4314/njt.v38i1.18

\title{
ASSESSMENT OF PERFORMANCE OF TURBO-ALTERNATORS AT THE JEBBA HYDROELECTRIC POWER STATION IN NIGERIA FROM 2005 - 2014
}

\author{
I. O. A. Omeiza ${ }^{1, *}$, H. A. Ojongbede ${ }^{2}$, C. T. Thomas $^{3}$ and B. J. Olufeagba ${ }^{4}$ \\ $\mathbf{1 , 3} \mathbf{4}$ Department of Electrical \& Electronics Engineering, Univ. OF ILORIN, ILORIN, KWARA STATE. Nigeria \\ 2, DePARTMENT OF EleCtrical \& INFORMATION ENGINEERING, LANDMARK UNIVERSITY, OMU-ARAN, KWARA STATE. NiGERIA \\ E-mail addresses: ${ }^{1}$ isaacavazi@unilorin.edu.ng; ${ }^{2}$ henryadeoye59@yahoo.com; \\ ${ }^{3}$ corneliustthomas@gmail.com; ${ }^{4}$ lobojay12@gmail.com
}

\begin{abstract}
The Nigerian power system consists of several sets of aged turbo-alternators (TAs) associated with frequent failures and limited installed capacity. This paper presents the results of a study of the performance of the turbo-alternators at one of the most important power stations in the country. The energy conversion characteristic of each of the turbo-alternators is studied by comparing the electrical power output with the total hydro-energy available on a daily basis. Similarly the availability was examined by generating the stochastic sequence of up-times for each TA. The results indicate that energy conversion remained essentially linear throughout the third decade of operations. Availability was however found to vary considerably from year to year with the worst performances occurring in the first five years - an indication of poor state of repair of the machines during that quinquennium. In conclusion, the results indicate that despite their age the TAs have many more years of service left provided maintenance is carried out diligently. Enhanced maintainability will however require both retro-fitting and a forward looking maintainability strategy.
\end{abstract}

Keywords: Hydro-Power, Turbo-Alternators, Energy conversion, Availability, Maintainability, Nigerian Power System.

\section{INTRODUCTION}

Electric power in Nigeria Power System [1,2] is a chaotic [3-5] and unpredictable affair characterized by frequent failures lasting for embarrassingly long durations of time. This phenomenon has led to a number of studies and actions that have had little but palliative effect on the system performance. Power in Nigeria is provided by a set of three major hydropower stations and a much larger number of thermal ones powered by petroleum gas and fuel oils. Two major hydropower stations - one located at the Kainji Dam and the other at the Jebba dam approximately $82 \mathrm{~km}$ downstream of the former on the River Niger, provide the most dependable power on the local grid and need to be studied carefully. The former station with an installed capacity of
160MW came on stream in 1968 and attained full capacity in 1978 [6].

The Jebba station with a collection of six identical machines (installed) each rated at $96.4 \mathrm{MW}$ was commissioned in 1985. At the time of this study, the station had been operating for two decades and was entering its third. While the turbo-alternators have provided power in some manner, this paper presents the results of studies of the conversion performance of the TAs and examines the overall viability individually. In order to do this, information about the flow through each TA, elevation of the head waters and the electrical energy developed was collected and analyzed as described below. This analysis is to further clarify the situation of the facility and hopefully provide hints/ pointers on how to achieve better performance in subsequent years. 


\section{METHODOLOGY}

Hydro turbo-alternators convert potential/ kinetic energy to rotational and subsequently to electrical energy [7]. Given that the turbo-alternators at the Jebba Hydroelectric Power Station (JHPS) derive their energy from a low-head reservoir with a head typically maintained around an elevation of 99 meters [8], the turbines were chosen to be fixed-vane Kaplan $[9,10]$ devices. In order to study the energy conversion properties of any turbo-alternator, it is essential to setup the expression for the potential energy and correlate this with the electrical energy produced over a given period.

A formal analysis of the arrangement can be made by applying Bernoulli's [11 - 13] equation to the water column between the head waters and the entrance to the turbine scroll case.

The total energy of the water at any point in the system is equal to the sum of potential energy and the kinetic energy of the water at that point.

In general, energy at the inlet of the penstock minus losses along the path to the tailrace will be equal to the energy absorbed by the turbine (EAT) plus the residual energy in the water at the tailrace.

$\mathrm{mgH}_{\mathrm{hw}}-$ Energy losses $=\mathrm{mgH}_{\mathrm{tr}}+\frac{1}{2} \mathrm{mV}_{\mathrm{tr}}{ }^{2}+\mathrm{EAT}$

$\therefore$ Energy absorbed by the turbine,

$$
\begin{aligned}
\mathrm{E}_{\mathrm{AT}}=\mathrm{mg}\left(\mathrm{H}_{\mathrm{hw}}\right. & \left.-\mathrm{H}_{\mathrm{tr}}\right)- \text { Penstock losses } \\
& - \text { scrollcase losses }-\frac{1}{2} \mathrm{mV}_{\mathrm{tr}}{ }^{2}
\end{aligned}
$$

However, the actual converted electrical energy depends on the efficiency of the turbines, $\eta_{\text {Turbine }}$, so that

$$
\begin{aligned}
E_{\text {electric }}=\eta_{\text {Turbine }} & E_{\mathrm{AT}} \\
& =\eta_{\text {Turbine }}\left[\mathrm{mg}\left(\mathrm{H}_{\mathrm{hw}}-\mathrm{H}_{\mathrm{tr}}\right)-\frac{1}{2} \mathrm{mV}_{\mathrm{tr}}{ }^{2}\right. \\
& \left.-\sum \text { losses }\right]
\end{aligned}
$$

Since, mass flow rate is equal to the density $\rho$, times the volume flow rate $\mathrm{q}, \mathrm{m}=\rho \mathrm{q}$

For a total time $T$, the flow is given by continuity equation [11]:

$$
\mathrm{Q}=\int_{0}^{T} A_{p s} \cdot V_{p s} d t=\int_{0}^{T} A_{t r} \cdot V_{t r} d t
$$

Let $\mathrm{T}_{\mathrm{up}}$ be the duration of time that TA worked, then $\mathrm{Q}=\int_{0}^{\mathrm{T}} \mathrm{A}_{\mathrm{tr}} \cdot \mathrm{V}_{\mathrm{tr}}(\mathrm{t}) \mathrm{dt}$

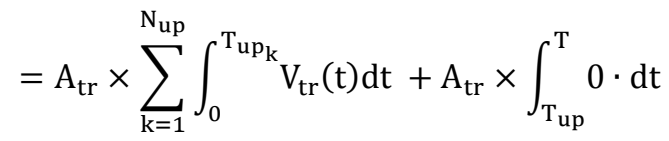

Where $\mathrm{T}_{\mathrm{up}_{\mathrm{k}}}$ is the $\mathrm{K}^{\text {th }}$ uptime in $\mathrm{T}$, the total uptime $\mathrm{T}_{\mathrm{up}}=\sum_{\mathrm{k}=1}^{\mathrm{N}_{\mathrm{up}}} \mathrm{T}_{\mathrm{up}}$ and $\mathrm{T}=1$ day.

$$
\begin{aligned}
\therefore \mathrm{E}_{\text {electric }}=\eta_{\text {Turbine }} & {\left[\mathrm{Q} \rho \mathrm{g}\left(\mathrm{H}_{\mathrm{hw}}-\mathrm{H}_{\mathrm{tr}}\right)-\frac{1}{2}{\mathrm{Q} \rho \mathrm{V}_{\mathrm{tr}}}^{2}\right.} \\
& - \text { Energy losses }]
\end{aligned}
$$

Where, $\mathrm{g}$ - Acceleration due to gravity $\left(9.81 \mathrm{~ms}^{-2}\right)$

$\mathrm{H}_{\text {hw }}$ - Elevation at the head waters of the reservoir (meters)

$\mathrm{H}_{\mathrm{tr}}$ - Elevation at the tailrace (meters)

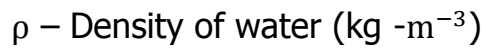

$\mathrm{m}$ - Mass of water per day

$V_{t r}-$ Velocity of water at the tailrace

$\mathrm{Q}$ - Total flow of water per day

$A_{\text {tr }}$ - Cross-sectional area of the tailrace

$\mathrm{E}_{\text {electric }}$ - Electrical energy generated per day

Applying the Bernoulli's equation at the Penstock exit (scroll case entrance), the flow of water through the turbine may be computed as follows.

$$
m g H_{h w}+\frac{1}{2} m u^{2}=\frac{m V_{\mathrm{ps}_{\mathrm{exit}}}{ }^{2}}{2}+m g H_{s c}+P_{L}
$$

$u=0$,

$$
\begin{aligned}
& \therefore \frac{V_{\mathrm{ps}_{\mathrm{exit}}}{ }^{2}}{2}=g\left(H_{h w}-H_{s c}\right)-P \\
& \left.V_{\mathrm{ps}_{\mathrm{exit}}}=\sqrt{2\left\{g\left(H_{h w}-H_{s c}\right)-P\right.}\right\}
\end{aligned}
$$

Where, $V_{\mathrm{ps}_{\text {exit }}}=$ Velocity of the water at the penstock exit $[12,14], P_{L}$ is penstock losses and $P$ is penstock losses per unit mass.

Hence, the volume flow rate,

$$
\begin{gathered}
q=A \times \text { velocity of water } \\
\therefore q=A \times\left\{\sqrt{2\left\{g\left(H_{h w}-H_{s c}\right)-P\right\}}\right\}
\end{gathered}
$$

Where $A$ is the effective area of the Penstock at its exit (scroll case entrance), $\mathrm{q}$ is the flow rate and $H_{s c}$ - Elevation at the entrance of the scroll case (meters); so that the total flow

$$
Q=\int_{0}^{T} q(t) d t=\int_{0}^{T} A v(t) d t
$$

In one day (24hours),

$$
Q=\int_{0}^{T} A_{P S} \cdot V_{P S} d t=\int_{0}^{T} A_{t r} \cdot V_{t r} d t
$$

Where $\mathrm{T}=86,000 \mathrm{~s}$.

Where the quantities in equation (11) are known, $Q$ can be computed to serve as a means of double checking the measured $\mathrm{Q}$ data, which can be substituted into equation (6) to give the electric energy produced.

In brief, it can be said that the relationship between the energy generated and the potential hydro-energy may be linear if the losses and turbine efficiency do not vary much. In practice, hydro-turbines are desired to maintain relative invariant operating conditions either by controlling the head or using 
regulators that maintain the shaft speed constant - a requirement that is essential for connectivity with a grid $[12,14,15]$. It is clear that in order to study the performance of such machines information about the flow rate, heads and dimensions will be needed. The Jebba case is very interesting because its turbines are fixed vane types that however require a tight control of the head waters elevation. This will be further considered as part of the study.

From eqn. (6), it is obvious that if the conversion constant $\left(\eta_{\text {Turbine }}\right)$ is not varying but dependent on the geometry of the penstock and the scroll case with the overall runner properties, then in the ideal case of a non-varying $\mathrm{Q}$ (volume of water released per day), the relationship should result in a constant amount of generated electrical energy corresponding to a single point in the plot. In general, energy conversion at the turbines may be determined from eqn. (6) and in principle satisfies a linear relationship where the available electrical energy is determined by efficiency constant $\eta_{\text {Turbine }}$. The study here is to explore the relationship between the gross potential energy and the actual electrical energy produced. Eqn. (6) provides a suitable rationale for evaluating the performance of the TAs by comparing the two quantities.

The available energy is a function of the head and where the outflow is available it can be computed and determined as a function of the product of the flow and the net elevation between the headwaters and the effective runner plane as in eqn. (6). Since the elevation at the hub plane is a constant, the resulting available energy is an affine function with the intercept being defined by the system's losses, while the slope is determined by the turbine's conversion efficiency. It should then suffice that the plot of estimated available energy versus the actual or measured electrical energy produced over the day should enable one decide the nature and condition of the TA.

The information available from the National Control Center (NCC) at Oshogbo, Nigeria for operations between 2005 and 2014 was used to develop a database for JHPS. The database, which had information for each day during the study period consists of about 3650 records of 16 fields each. The fields include the daily outflow measured at the tailrace, the head water elevation, tail water elevation, and the energy generated by each of the turbo-alternators (TAs).
The second element of the study involves identifying and deducing the condition of each TA as represented by its conversion efficiency. The theoretical available energy for power generation was computed using the measured outflows from each TA. The actual energy available as stated above requires the subtraction of the losses in the penstock principally. While this could be estimated, it suffices to note that the TAs are fixed-vane Kaplan types, as such there heads are managed by the operators to maintain a value that varies very little compared with the absolute value of the elevation $[9,10]$. Given such an operating style where the head is maintained by the operators within very tight margins, the losses will be relatively constant. For a machine in perfect condition this would appear as single point where the value would satisfy the equation above. For an actual machine working after two decade since commissioning, the plot of the computed versus the total energy would be a scatter plot reflecting both the conversion features and the availability. Using the data from the database for the station, EXCEL software was used to extract and display the values. In order to improve understanding of the energy available over the period of the study, it was essential to carry out a statistical study of the energy developed during the period of the study. Using the values obtained from the database, a frequency histogram was constructed for each of the turbines over the given period. The results are shown in Figs. 6 to 10 . The actual measured energy varied from 0 Mwh to maximum of 2392 Mwh. Of interest is the selection of the intervals which was resolved using Sturges' rule [16]. The result culminated in a grouped data consisting of 14 classes with a class interval of $184 \mathrm{Mwh}$. Due to preliminary results it was decided to study the variation in amount of energy generated within a total period of ten years and the two quinquennia that defined the decade. The results for each TA are as shown in Figs. 6 to 10 .

\section{RESULTS AND DISCUSSION:}

The operational data configured into an EXCEL database was then used to determine the behavior of each TA. The results are as shown in Figs. 1 to 5 with respect to the energy conversion between the available hydro energy and the total electrical energy produced over the day. From the graphs, it is evident that the best fit curve in all cases is linear with a near negligible intercept on the $x$-axis. The slope of the best fit provides an indication of the manner whereby 
energy is converted by the turbo-alternator. From the shape of the graphs, it is clear that energy conversion is consistent. The fact that the plot is not a point merely indicates that the TA's do not successfully work throughout each day and in a way, the offset from the maximum possible, reflect a sort of virtual capacity. A further examination of the curves reveal that while in an ideal situation a TA would have all points concentrated at one location in response to an unvarying $Q$, the operations in this case are spread over a curve that had a best fit that is linear. Tests carried out in an EXCEL-VBA program using polynomial fits revealed that the best fit was a linear one. The values of the fits are as shown on the graphs. Since the fit exhibited a relatively good one, the slope could be used to determine the efficiency of conversion. The spread of points along the linear path however indicate that the total energy generated varied from day to day. This also is consistent with the fact that the TAs operate for a

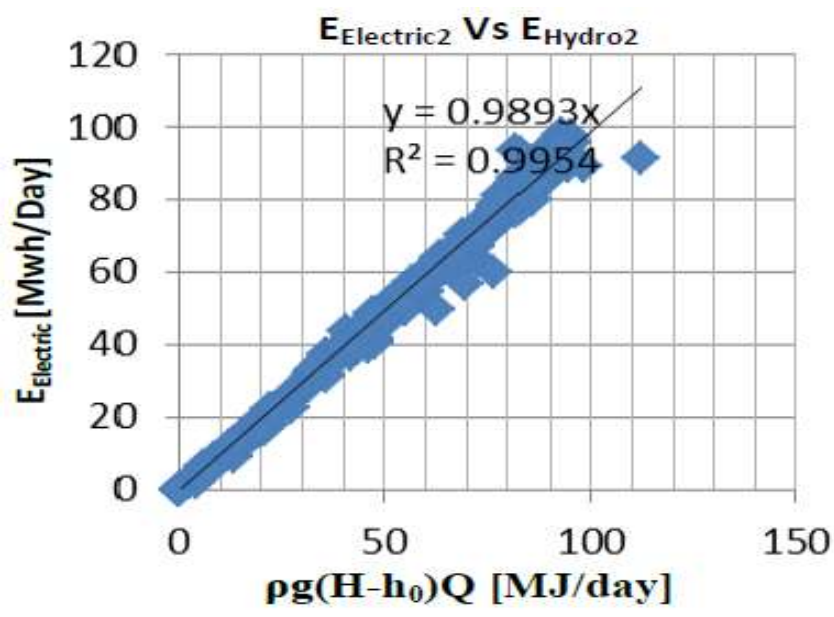

Figure 2: Conversion Performance of Turbo Alternator 2

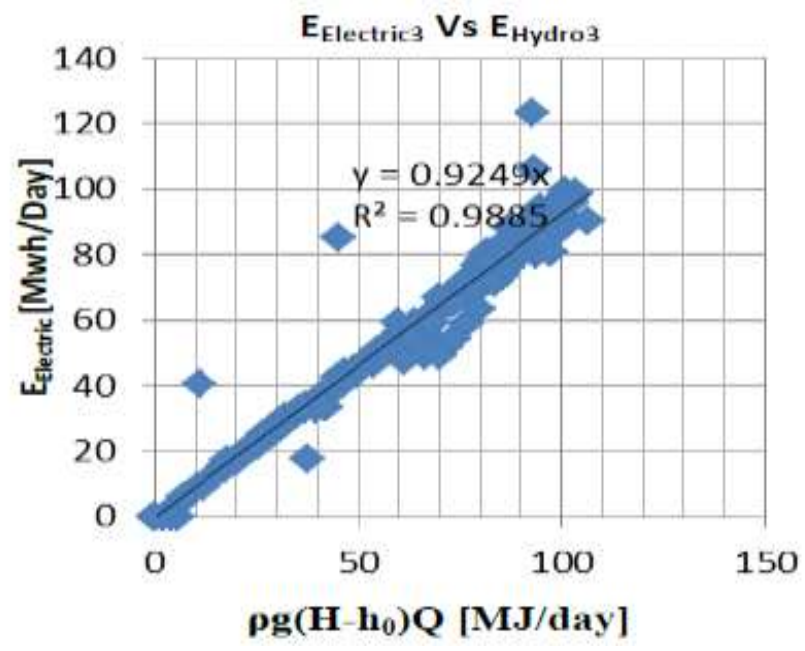

Figure 2: Conversion Performance of Turbo Alternator 2 number of hours less than the whole day either due to deliberate operator-triggered shutdowns or random failures of the TAs.

It can be further deduced that the losses in the penstock are relatively minor although an accurate determination of the residual effects would need more precise measurements than is presently available. This implies that the first test of the condition of each TA has been passed. Despite an age of over 20 years, the penstock and tunnel do not appear to be causing any appreciable/ noticeable degradation of the available energy.

It is however necessary to carry out further analysis so as to determine whether the plants are making adequate use of the available energy and if some drastic measures may be required. In order to do this, further analysis was carried out on the energy produced over the decade. A study of the histogram of energy produced was carried out using Sturge's intervals and in the EXCEL-VBA [17] environment.

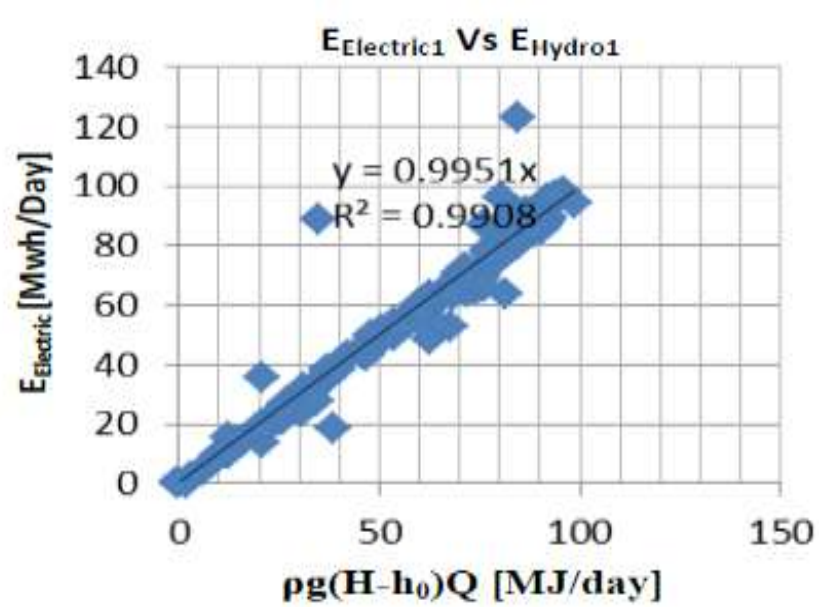

Figure 2: Conversion Performance of Turbo Alternator 1

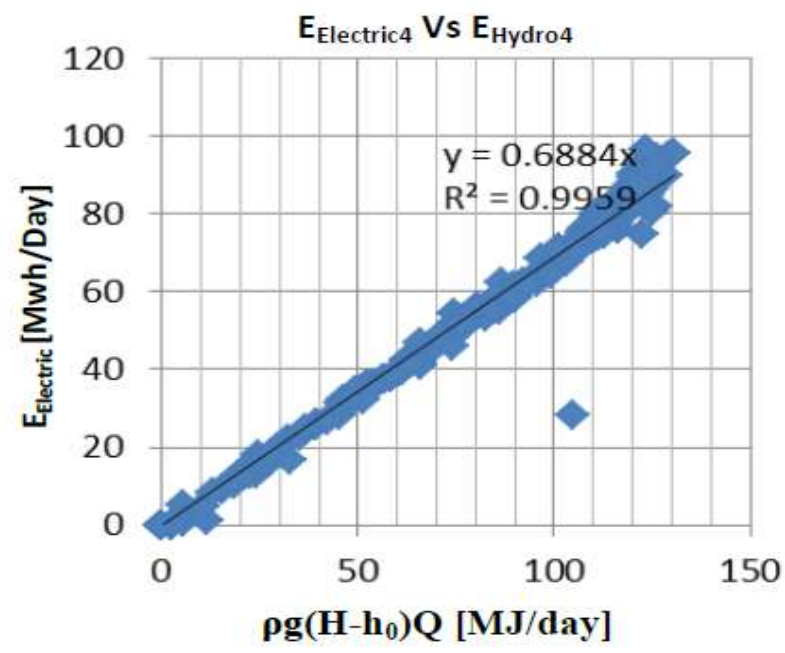

Figure 2: Conversion Performance of Turbo Alternator 2 


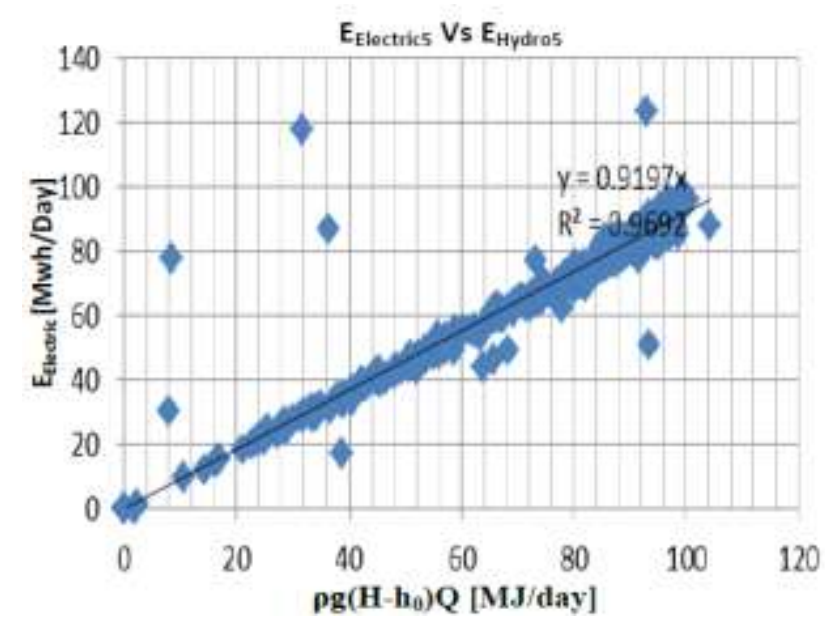

Figure 5: Conversion Performance of Turbo alternator 5

The results are as shown in Figures 6 to 10. The histograms show the combined distribution for the decade and the two individual quinquennia.

In Figs. 6-10, the frequency unit is the number of days a particular energy is generated in the ten years investigated or five years in each quinquennium. The daily energy generated by all the TAs is between 0 and $2576 \mathrm{MWh}$. The data were grouped into 14 classes with a class interval of $184 \mathrm{MWh}$.

A study of the machines by comparison between the distribution of the production in the two quinquennia indicates that in the first quinquennium (five year period), all the machines tend to be concentrated at the two ends of the energy production range. This also tends to reflect a greater concentration of time when the machines were down. The second quinquennium on the other hand in all cases manifest a reduction in the down/ unproductive period whilst there is a shift from this low production zone (in the neighborhood of zero) to more mid-range values. This is indicative of improved performance although the occurrences of values in the lower to mid regions of production reflects the intermediate improvements when repairs and refurbishment is carried out but the work is not completely proven. Indeed this analysis confirms that the machines were subjected to repairs and/ or refurbishment in the second quinquennium although the effect did not fully restore them to pristine condition.

The plots of $E_{\text {electric }}$ against available hydro energy for all the turbines are found to be linear. With the head waters being held constant, a very low velocity at the tailrace and a varying $Q$ (daily flow), in eqn. 1 ; the plots can only be linear if the turbine efficiency is a constant. If the turbine efficiency had varied over the years, the plots would not have been linear. In addition, observation of the plots shows that the intercepts on the ordinate axes are close to zero which can only be as a result of negligible energy losses, going by eqn. 1 .

As such, the results of this study reveal that the condition of the path to the turbo-alternators continue to exert a near negligible energy loss and may require little or no serious maintenance for the foreseeable future due to the low intercepts of the plots. The energy conversion characteristics of the TAs similarly follow the same trend even though the actual availability of each machine will require further study.

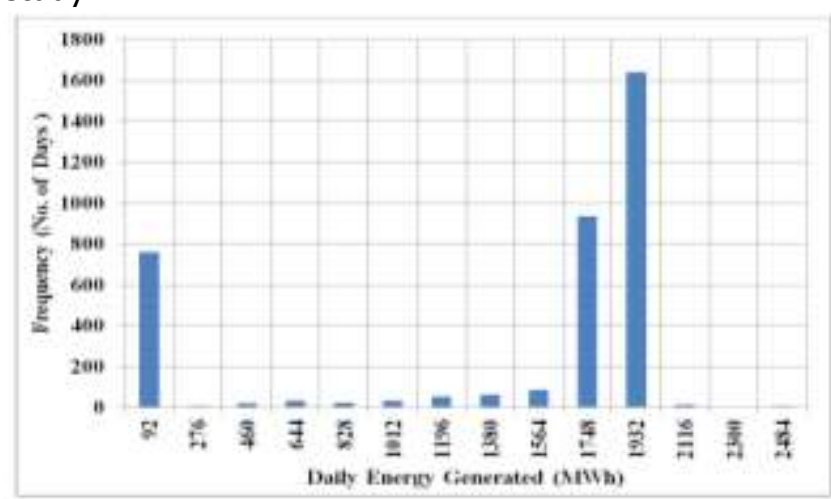

(a)

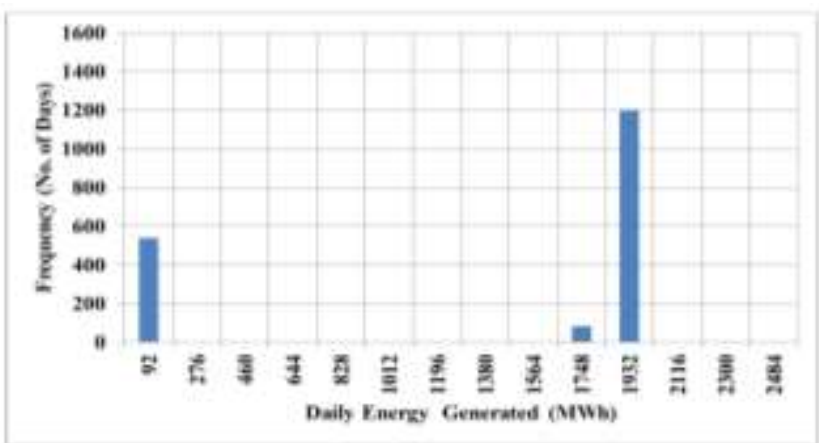

(b)

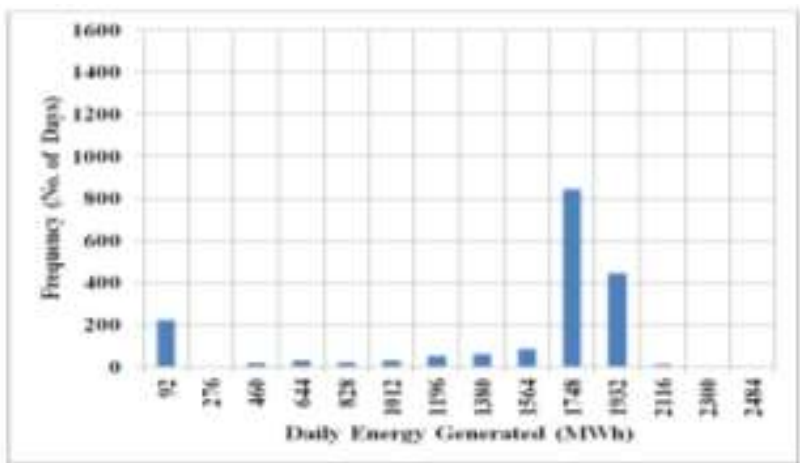

(c)

Fig. 6: Histogram of energy produced by TA1 (a) $2005-$ 2014 (b) Quinquennium 1 (c) Quinquennium 2 


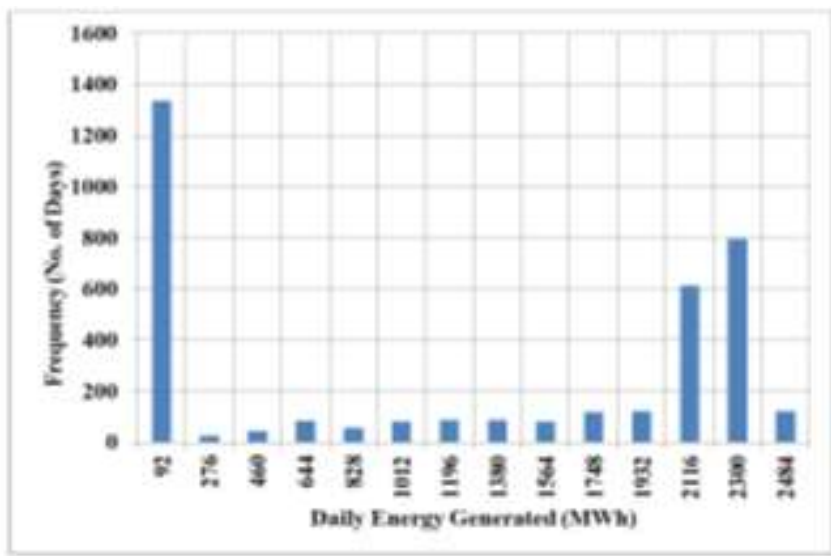

(a): $2005-2014$

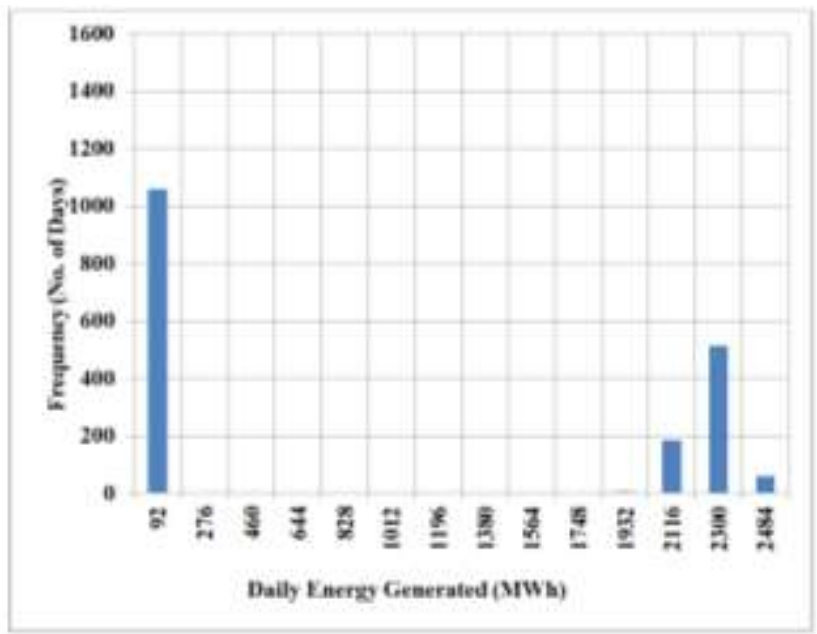

(b): Quinquennium 1

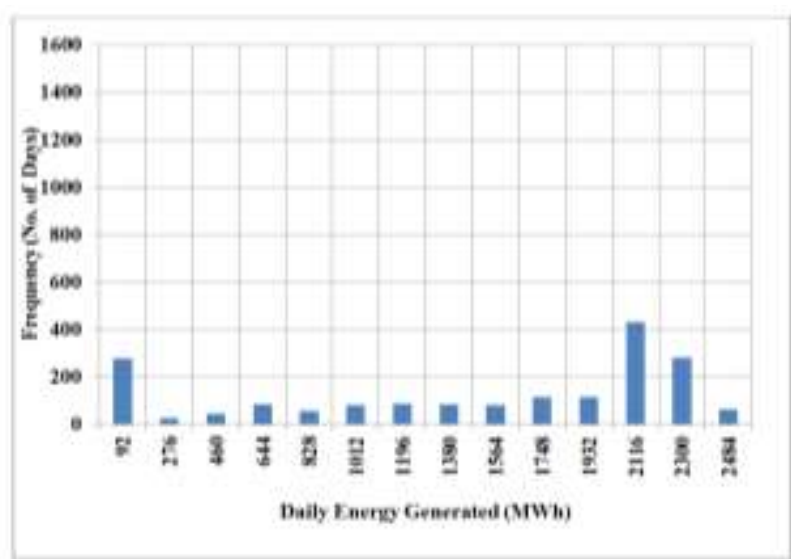

(c): Quinquennium 2

Fig. 7: Histogram of energy produced TA2

The presence of points close to the origin indicates the existence of reduced operational hours which seem to be predominantly due to failures rather than operator-triggered shutdowns due to either water shortage or some external factor that could damage one or more of the TAs.

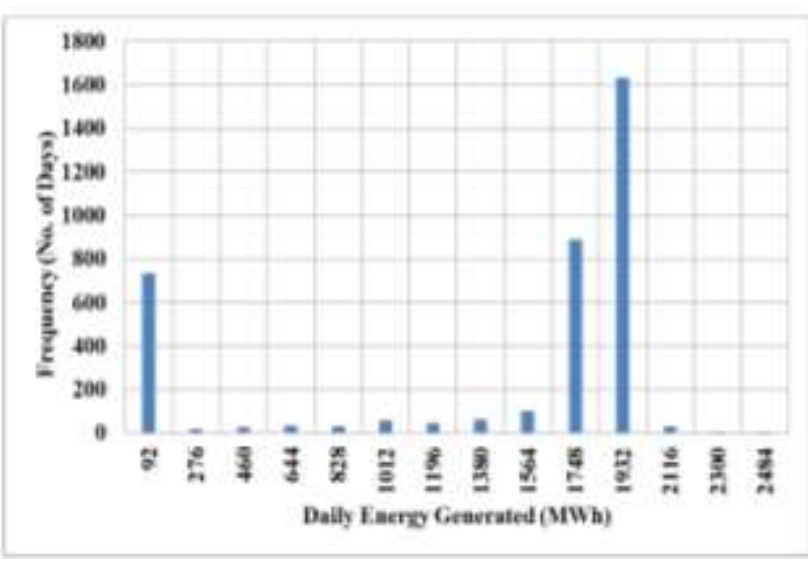

(a): $2005-2014$

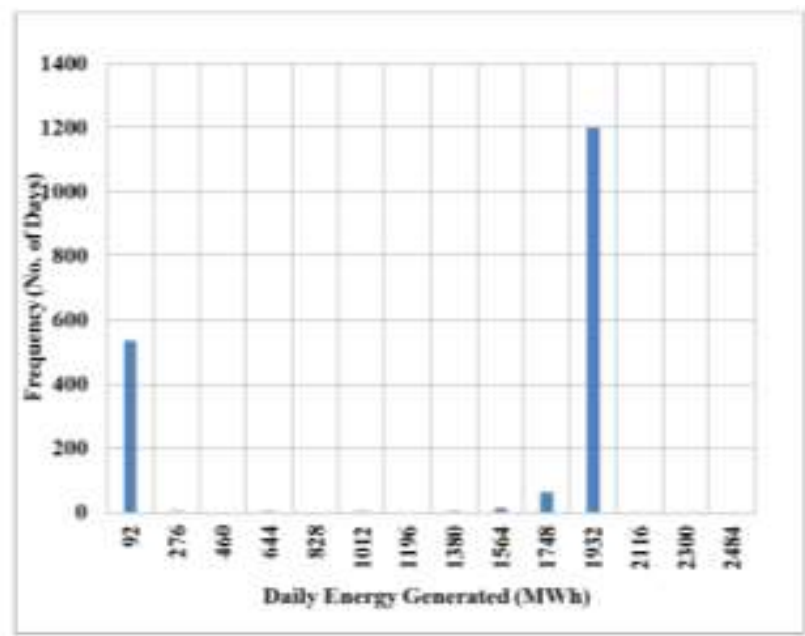

(b): Quinquennium 1

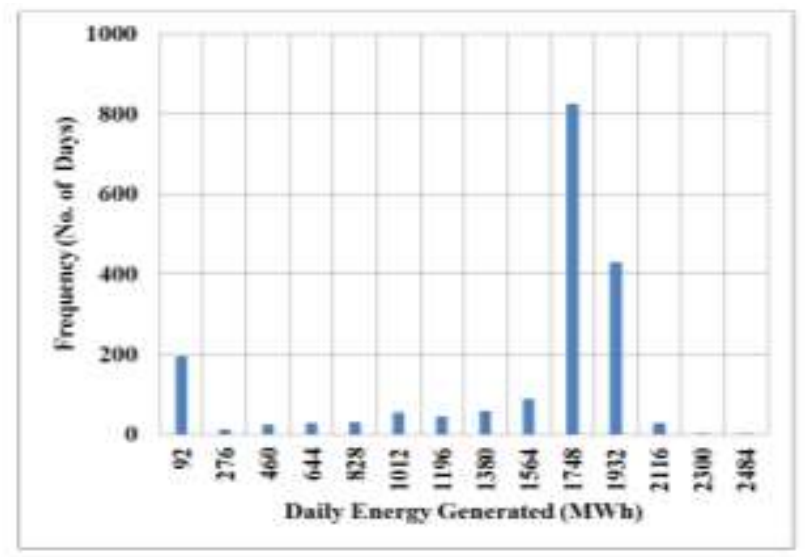

(c): Quinquennium 2

Fig. 8: Histogram of energy produced by TA3

\section{CONCLUSION}

The analysis carried out above confirms the fact that the TAs in the station are in principle still very useable despite their age, although the decision to refurbish them will still depend on further studies of the nature of the failures. There is however an obvious need for improving availability if the station is to be operationally satisfactory. 


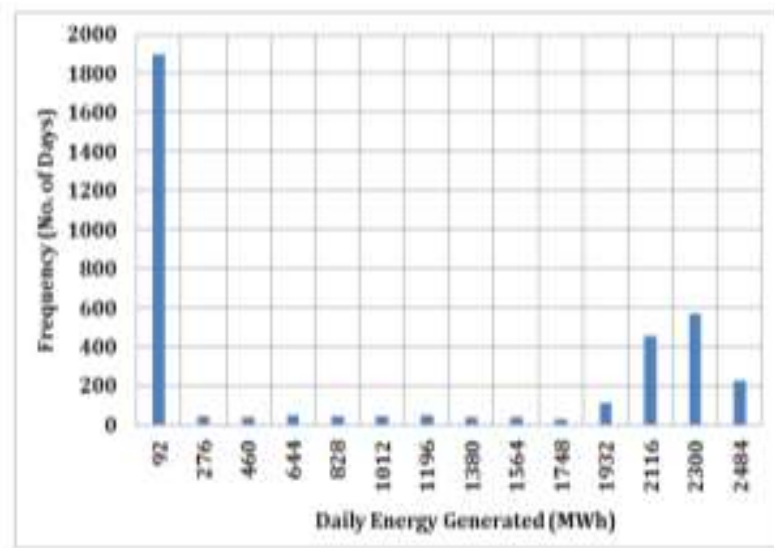

(a): $2005-2014$

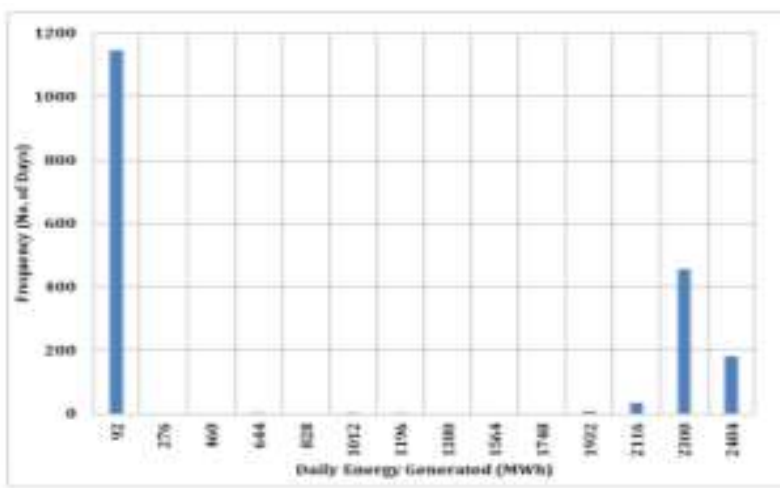

(b): Quinquennium 1

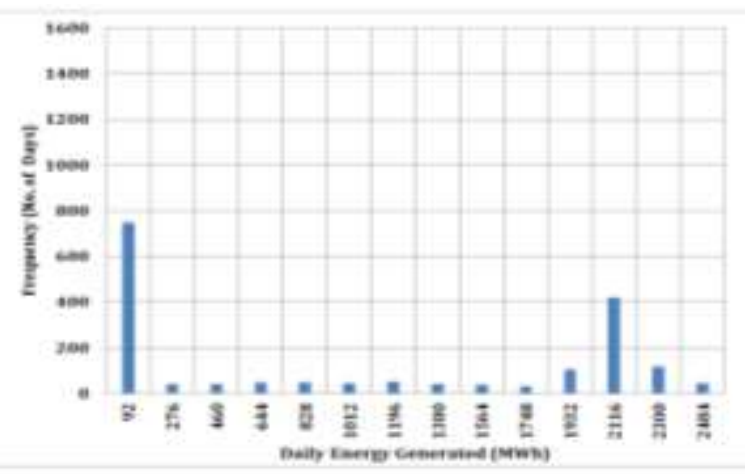

(c): Quinquennium 1

Fig.9: Histogram of energy produced by TA4

\section{REFERENCES}

[1] Government of the Federal Republic of Nigeria. "Development of Electricity Industry in Nigeria (1960 -1989)", Niger Power Review, pp. 10 - 15, 1989.

[2] Ale, T.O. "Analysis, Modeling and Simulation of Reliability of Generation of Kainji Hydro Power Station, Nigeria", Unpublished Ph.D. Thesis, Dept. Electrical and Electronics Engineering, Federal University of Technology, Akure, Nigeria, 2014.

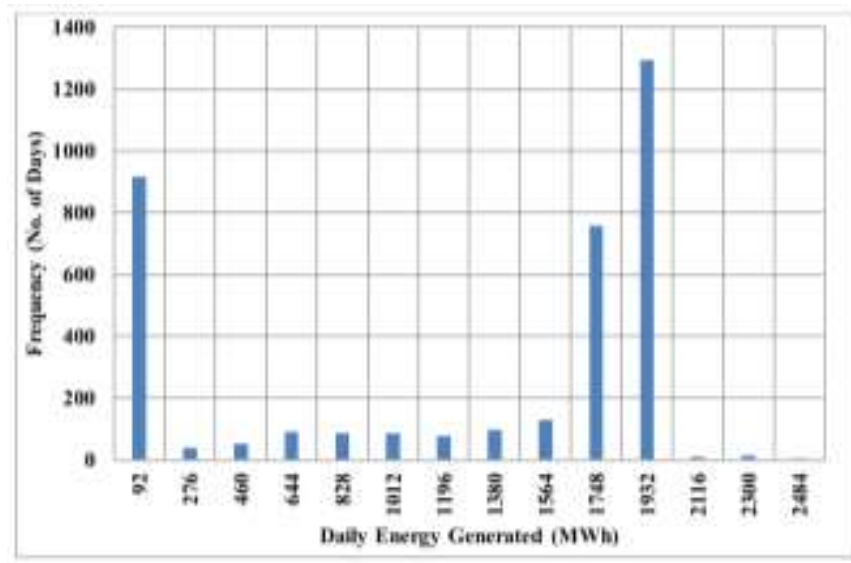

(a): $2005-2014$

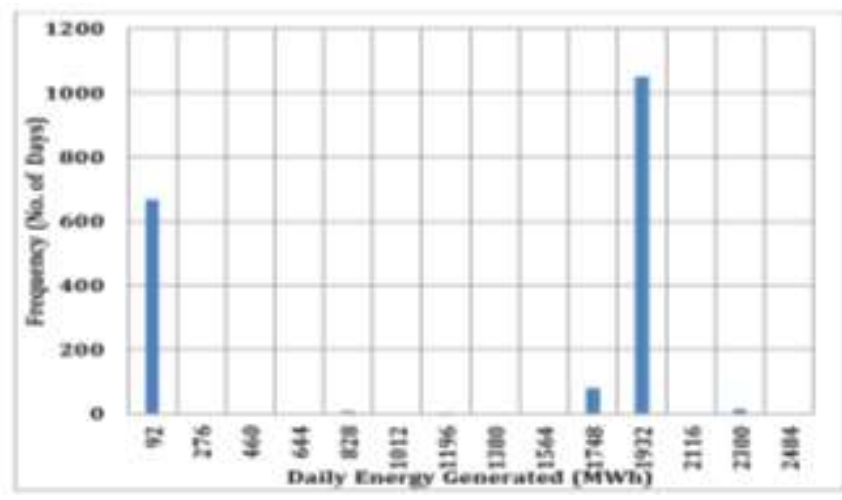

(b): Quinquennium 2

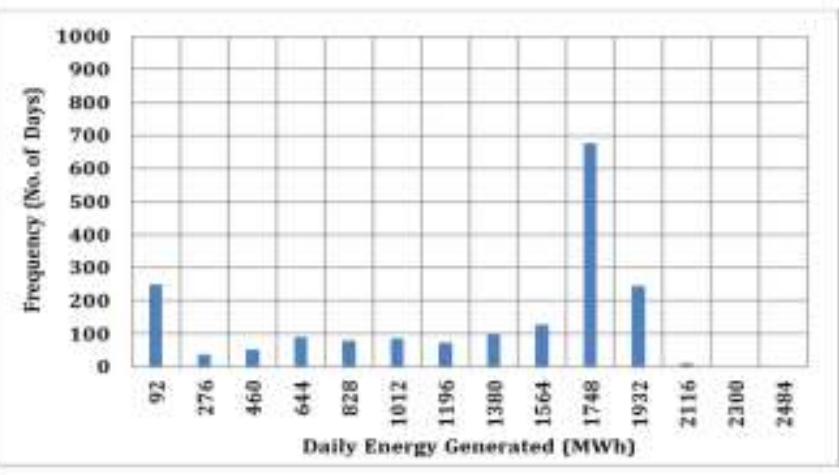

(c): Quinquennium 2

Fig. 10: Histogram of energy produced by TA5

[3] Oluwole, A., Samuel O., Festus O., and Olatunji O. "Electrical Power Outage in Nigeria: History, Causes and Possible Solutions", Journal of Energy Technologies and Policy, Vol.2, Number 6, 2012

[4] Ijewere, A.A. "The Management of Electricity Power Supply in Nigeria: Problems and Prospects", Journal of Research in National Development, Vol.9, Number 2, pp. 173 - 185, 2011.

[5] Okoro, O. I. , Govender, P. and Chikuni E. "Power Sector Reforms in Nigeria: Opportunities 
and Challenges", Journal of Energy, South Africa. Vol.18, Number 3, pp. 52-57, 2007.

[6] Ale, T. O. and Olufeagba, B. J. "A study of the Generation Performance of the Kanji Hydro Power Station", $3^{\text {rd }}$ International Conference on Engineering Research \& Development: Advances in Engineering Science \& Technology, Benin City, Nigeria, September 7 - 9, pp. 1706 - 1714, 2010.

[7] M. Manno. "Hydraulic Turbines and Hydroelectric Power Plants" Lecture notes for Energy Systems Course, Department of Industrial Engineering, University of Rome, Tor Vergata, http://didattica.uniroma2.it/assets/uploads/corsi/ 144713/hydro.pdf, Accessed on July 22, 2015.

[8] Thomas C. T. "The Analysis of the Jebba Hydroelectric Power Station in it's Third Decade", Unpublished M. Eng. Thesis, Dept. of Electrical and Electronics Engineering, University of Ilorin, Ilorin, Nigeria, 2014

[9] Mechnol,"Kaplan Turbine and its Design, working Principle", http://www. mechnol.com/Kaplanturbine-abd-its-design-working-principle.html, Accessed on March 3, 2015.

[10] Mishra, G. "Kaplan Turbine", http://the constructor.org/practical guide/Kaplanturbine/2904/, Accessed on March 03, 2015.

[11] White, F. M. Fluid Mechanics, $7^{\text {th }}$ Edition, MccGraw - Hill Higher Education, 2011.
[12] Kovalev, N.N. Hydroturbines Design and Construction, National science Foundation, Washington D.C.,1965, available at https: //www.frenchriverland.com/ hydroturbines_design_and_construction_n_n_kov alev.htm, Accessed on $9^{\text {th }}$ April , 2018

[13] Topliceanu, L., Gabriel, P. and Furdu, I . "Functional Problems and Maintenance Operations of hydraulic Turbines", Technology Education Management Informatics, Serbia, 5 (1), pp 32 - 37, 2016.

[14] Waski, T. et.al, Computer Applications in Hydraulic Engineering, $8^{\text {th }}$ Edition, Bentley institute press, 2010.

[15] Thapar, O. D. Modern Hydroelectric Engineering Practice in India: Electro-Mechanical Works, Vol.1, Indian Institute of Technology, Roorke, available at https:// www.iitr.ac.in/departments/AH/pages?publication s Downloads+Modern Hydroelectric Engg Practi ce by Prof $0 . .$. , Accessed on $11^{\text {th }}$ April 2018.

[16] Montgomery, D. C. and Runger, G. C. Applied Statistics and Probability for Engineers, John Wiley \& Sons Inc., USA, 3rd Edition, pp. 124 379, 2003.

[17] Walkenbach, J. Excel 2010 Power Programming with $V B A$, Wiley Publishing, Inc. USA, pp. 39-43, 2010. 